Western Washington University

Western CEDAR

Environmental Studies Faculty and Staff

Publications

Environmental Studies

3-10-2011

\title{
What Research Should be Done and Why? Four Competing Visions among Ecologists
}

Mark W. Neff

Western Washington University, mark.neff@wwu.edu

Follow this and additional works at: https://cedar.wwu.edu/envs_facpubs

Part of the Environmental Studies Commons

\section{Recommended Citation}

Neff, M. W. (2011), What research should be done and why? Four competing visions among ecologists. Frontiers in Ecology and the Environment, 9: 462-469. doi:10.1890/100035

This Article is brought to you for free and open access by the Environmental Studies at Western CEDAR. It has been accepted for inclusion in Environmental Studies Faculty and Staff Publications by an authorized administrator of Western CEDAR. For more information, please contact westerncedar@wwu.edu. 


\title{
What research should be done and why? Four competing visions among ecologists
}

\author{
Mark W Neff
}

Information we collect about our planet depends, in part, on the questions scientists ask regarding the natural world. Asking other questions might lead to different innovations and alternative understandings of policy problems and their potential solutions. With a seemingly infinite number of potential study subjects but limited resources with which to study them, why have we chosen to focus on the topics that we have? Here, I present a Q-method study that explores ecologists' thought processes as they evaluate the merits of potential research topics. The participants, ecologists attending the Ecological Society of America's 2008 Annual Meeting, nominally agreed with one another that their discipline should contribute to solving environmental problems, but they interpreted that goal differently. This study uncovers four competing visions that ecologists have for their discipline. On the basis of these findings, I contend that ecology might be more effective in informing policy if priority setting were a more deliberative process and open to insights from individuals and institutions outside of ecology.

Front Ecol Environ 2011; 9(8): 462-469, doi:10.1890/100035 (published online 10 Mar 2011)

W hat scientists study is not dictated by nature, but rather is the result of human choices influenced by social, cultural, and technological factors that, to date, have not received much attention. The subjects ecologists study and the methods they use have changed dramatically over time, which invites inquiry into the factors that drive such change (Neff and Corley 2009). Individual scientists' preferences are an important aspect of research priority setting, as individual scientists exercise varying levels of control over their own selection of research projects, and scientists collectively populate and advise many of the institutions that constrain and influence individual scientists' options. Many previous efforts to understand what motivates scientists' selection of research problems have focused on their strategies for securing funding and build-

\section{In a nutshell:}

- Scientific research agendas influence broader sociopolitical understanding of policy problems

- Ecologists exercise considerable power in establishing research priorities

- In evaluating statements about knowledge needs, ecologists simultaneously evaluate and consider: (1) the ideal role of science in policy, (2) what environmental problems are most pressing, and (3) what solutions they believe to be possible and palatable to themselves and others

- Priority-setting forums open to those outside ecology could clarify the above and help ensure that ecological research is effective in informing policy

Consortium for Science, Policy and Outcomes, Arizona State University, Tempe, AZ; current address: Department of Environmental Science, Allegheny College, Meadville, PA (mneff@allegheny.edu) ing their scientific reputations (Gieryn 1978; Zuckerman 1978; Ziman 1981; Ziman 1987). Other processes are at work, however, including the desire to conduct research relevant to policy problems (Merton 1979; Worster 1994). By inviting ecologists to evaluate potential research priorities and investigating their thought processes as they do so, this paper begins to explain how research agendas emerge in science. This work yields insights into why some types of research - but not others - are conducted. Understanding how disciplinary research trajectories emerge is critically important because the knowledge we have about the environment shapes, in a fundamental way, what we perceive to be problems and what potential policy tools we can consider for addressing those problems.

In the US, research priority-setting processes within disciplines are largely handled by disciplinary communities, with the justification that quality-control processes built into the scientific system - including peer review, tenure standards, and scientific norms - serve to identify the most important and productive research projects (Polanyi 1962; Chubin and Jasanoff 1985; Rip 1985; Chubin and Hackett 1990; Barke 2003). Scientists' choices of research topics are constrained to varying degrees by funding bodies, employers, and other actors. Nevertheless, individual scientists often have extensive leeway when selecting projects and methods (Gieryn 1978; Ziman 1981; Ziman 1987), and they themselves populate many of the institutions and contribute to the policies that shape the choices made by others (WebPanel 1). Within broad-scale, externally imposed strictures, disciplinary research portfolios (ie the collected work produced) largely reflect the aggregate evaluations by that discipline's scientists of the merits of potential research projects (Weinberg 1963). They are not, however, merely averages of those evaluations 
because ecologists do not have equal access to prioritysetting processes.

This paper examines the mental frameworks that ecologists use to evaluate the merits of potential research priorities and highlights some of the challenges these disparate ideas pose for ecologists and their funders, who wish the knowledge they produce to be helpful in informing human actions and/or policies. Individual scientists - regardless of where they obtain their research support - influence others' understanding of the merits of potential research topics (eg through peer review, serving on advisory panels, and by training students; see WebPanel 1); the findings of this study therefore have direct relevance to science funded by mission-driven agencies, as well as that funded by organizations with mandates to finance basic science.

\section{Methods}

I utilize Q method - a research method used to study an individual's subjectivity (Brown 1980; McKeown and Thomas 1988; Robbins and Krueger 2000; Woolley and McGinnis 2000; Salazar 2009) - to assess what ecologists view as important work for their discipline and how they arrive at these conclusions. The $\mathrm{Q}$ method is designed to elicit participants' ways of thinking about a topic by establishing a simulated dialogue between participants and the ideas of their colleagues (Robbins and Krueger 2000). To minimize investigator interference in participants' thought processes, Q method does not rely on administering investigator- and theory-derived questions in a survey or interview format, but rather allows participants to respond to and rank-order statements that they and their colleagues have made. In this study, participants ranked a set of ecology research priority statements drawn from the literature. I then used multivariate data reduction techniques to identify groups of participants who ranked the statements similarly. I did not have to presuppose or intuit what ideas, categories, comparisons, and considerations were likely to be important to participants; rather, I solicited that information from participants as they completed the exercise and associated interview. The information was then compiled, analyzed, and interpreted. This method uncovers shared ways of thinking about the topic at hand.

To begin a Q-method study, the investigator collects a diverse suite of statements about the topic of interest from participants and those with similar backgrounds (Brown 1980). The investigator then selects a subset of those statements, creating what is known as the Q sample. This sample is not intended to be random, nor does it have to be representative. Instead, the statements are selected to ensure that participants have a diverse set to which they can respond (Brown 1980). In conducting this study, I identified 540 statements of research priorities, knowledge needs, and disciplinary imperatives culled from 31 scientific and policy documents written by ecologists, their professional associations, funding agencies, and the US National Research Council (the documents are listed in WebPanel 2). Using a structured sampling regime (Brown 1980), I selected a $Q$ sample of 32 statements that covered the breadth of the original set of statements (Table 1).

The next step is to administer the Q survey to a pool of participants. Because the $\mathrm{Q}$ method is designed to identify and characterize ways of thinking about and understanding an issue - and not to quantify the prevalence of those ways of thinking - the participant sample does not have to be representative of the population (Brown 1980; McKeown and Thomas 1988). With the aid of a research team, I recruited 77 participants at the 93rd Annual Meeting of the Ecological Society of America in July and August 2008, and 10 participants from among ecology faculty and graduate students at a research-intensive university in the US. This pool of participants allowed me to conclude with confidence that the mental frameworks and decision-making considerations identified in this study are present within the ecological research community. The existence of these multiple competing visions is the finding upon which the conclusions are based. Because the participants are not randomly sampled in Q-method studies, the method does not allow me to conclude that these are the only attitudes and approaches held by ecologists or that these findings are representative of the broader community, and it does not allow for analysis of the demographic, disciplinary, or employment backgrounds of participants who support particular research priorities (Brown 1980).

Following standard methods (McKeown and Thomas 1988), all participants were instructed to rank the 32 statements, printed on 3" $\times 5$ " cards, from "most agree" to "most disagree", as follows: participants were first asked to read through all of the statements and create three piles - the cards they agreed with; those they disagreed with; and those that were not salient, did not make sense, or did not elicit a strong response. Next, participants were instructed to find the two statements they most agreed with, or viewed as the most pressing for ecologists to address, from their own "agree" piles. They were then asked to find the two they most strongly disagreed with from their "disagree" pile. Alternating between agree and disagree and drawing from the middle pile when necessary, the participants ranked all the statements into a forced Gaussian distribution with nine categories, from "most disagree" $(-4)$ to "most agree" (4). The number of statements allowed in each category was as follows: 2,3 , 4, 4, 6, 4, 4, 3, 2 (Figure 1).

Following the ranking exercise, the research team interviewed all participants and took exhaustive notes in order to uncover their reasoning and logical frameworks. More extensive follow-up interviews, lasting between 20 minutes and 1 hour, were conducted with eight participants. These were recorded and later transcribed. A written survey administered to all participants collected data on demographics, training, topical and regional expertise, and current and past employment. 


\section{Table 1. Ecology research statements and factor scores}

\begin{tabular}{|l|}
\hline Factor \# \\
\hline \# participants \\
\hline
\end{tabular}

\begin{tabular}{|c|r|r|r|r}
\hline 1 & 2 & 3 & 4 & Rank \\
\hline 20 & 27 & 6 & 12 & $x / 32$ \\
\hline
\end{tabular}

Researchers should determine the best practices for the communication of scientific information and uncertainty among scientists, policy makers, and the public, and understand how the information and uncertainty about outcomes are received, understood, and acted upon

Ecological research should expand beyond national borders and ethnic differences because the solutions to environmental problems and sustainability are inherently international and multicultural

Researchers should identify the effects of human perturbations of biogeochemical cycles (including release of contaminants) on ecosystem functioning on land, and in the atmosphere and oceans

Researchers should integrate population, ecosystem, and socioeconomic models to improve understanding of landscape fragmentation, including assessing how coupled human and natural landscapes function

Researchers should study how altered ecosystem dynamics affect ecosystem services

Researchers should explore how the structure within biological communities (eg genetic structure, composition, or species diversity) is linked with the functional aspects of ecosystems (eg productivity, nutrient cycling, or sequestration and release of contaminants)

Researchers should work to accelerate the basic science of restoring damaged and degraded ecological systems by developing, testing, and applying principles of restoration ecology

Researchers should work to determine the ecological causes and consequences of global climate change by quantifying and modeling the links between biospheric and global change

Researchers should study how changes in the relative abundance of native species alter community structure and ecosystem processes

Researchers should explore how the changes in ecosystems brought about by human settlement and management influence future human choices

Researchers should identify the economic and social trade-offs for different restoration options

Ecologists should create a rapid-response team that draws on ecological expertise in responding to legislative and executive branch proposals, which would result in a larger role for ecological knowledge and ecological scientists in the legislative and policy processes that impact sustainability

Researchers should study what criteria should be used to determine when to intervene to deal with invasive species

Researchers should study what the roles of soil biodiversity (and specifically, little-known groups such as mites or nematodes) are in ecosystem function, resilience, and recovery

Researchers should study how specific environmental changes (eg deforestation, drought) alter transmission of infectious diseases in human populations

Researchers should seek to determine the evolutionary consequences of anthropogenic and other environmental changes

Researchers should study the relative influences of human drivers (eg population, motives, and rules), and biophysical drivers (eg topography, weather, climate) of change in working and urban systems

Researchers should study the ecological implications at an international scale of conservation actions and policies adopted within the US

Researchers should study the consequences of biofuel production for biodiversity at field, landscape, and regional levels

Researchers should study how reliant animal and plant populations in small nature reserves are on the maintenance of habitat in surrounding non-protected areas

Researchers should seek to incorporate processes at all scales, from molecular to global, into comprehensive environmental models

Biodiversity surveys should be closely tied to experimental studies of the effects of biodiversity and species composition on ecosystem function and provision of services

Just as nuclear accelerators have proved to be essential for advancing our knowledge of subatomic physics, networks of infrastructure that facilitate and accommodate well-replicated ecological experiments are essential for advancing our knowledge in ecology and environmental science

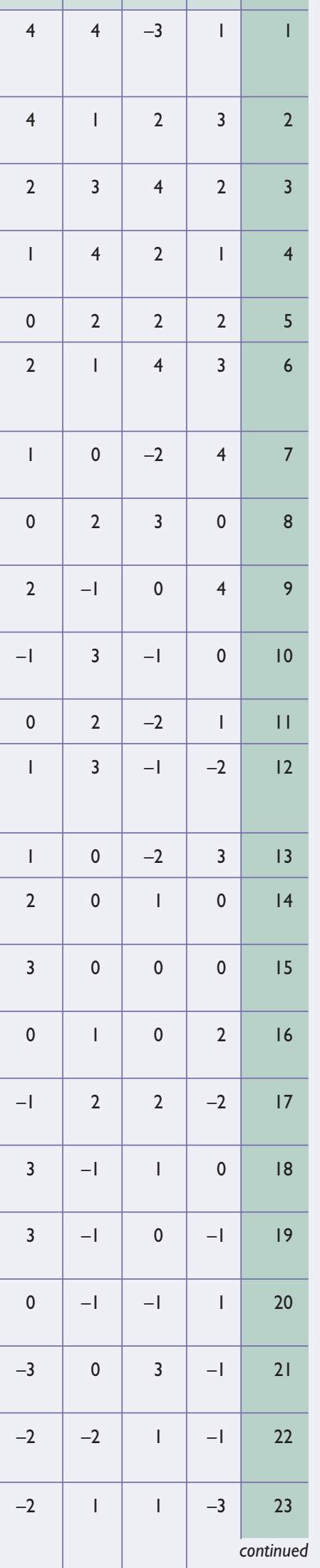


Table 1. Ecology research statements and factor scores - continued

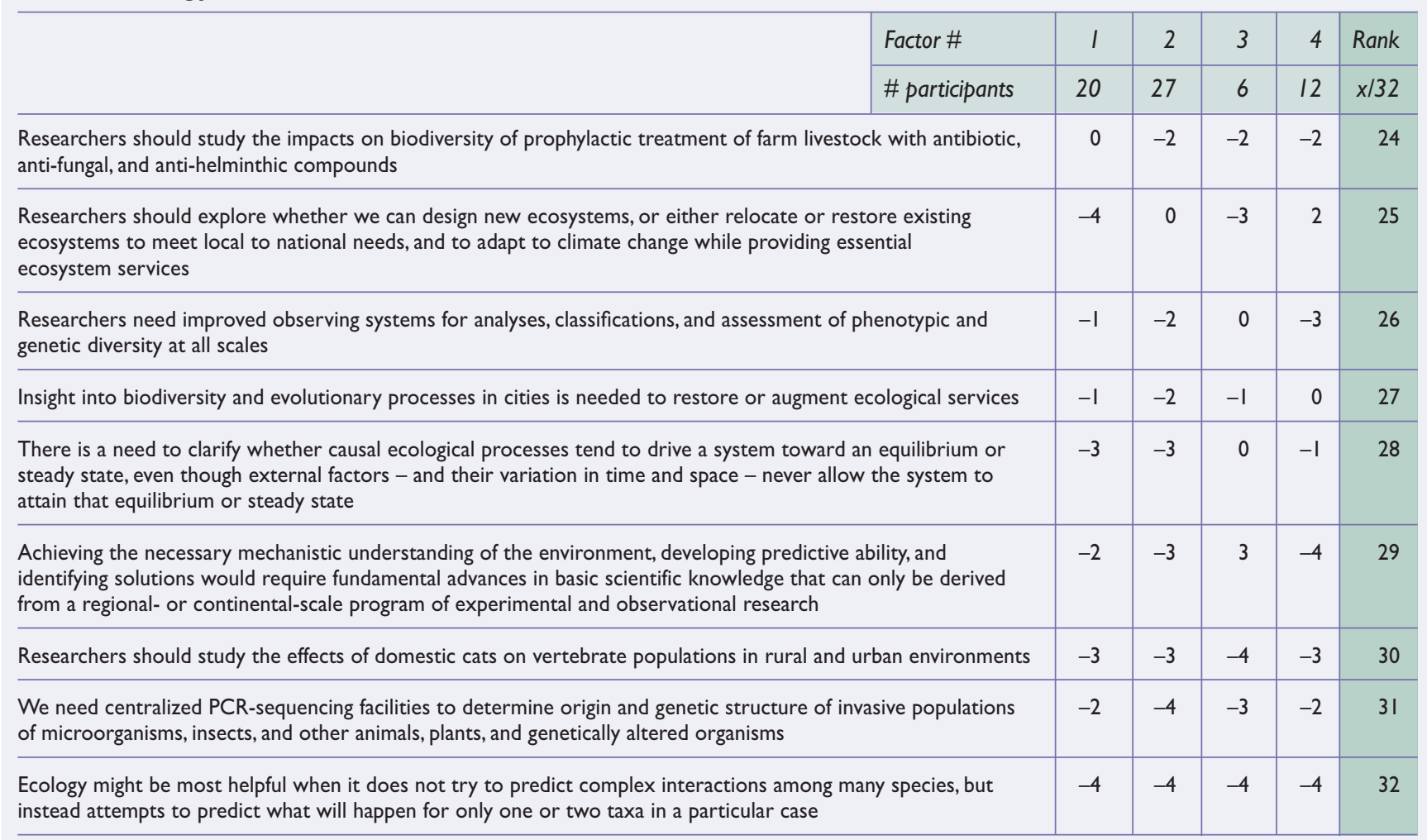

Notes: Scores range from -4 (most disagree) to 4 (most agree). The last column shows the overall popularity rankings of the statements, averaged across the four factors.

PQMethod (v 2.11) and SPSS (v 16.0) software packages were used for statistical analyses of the statement rankings. Participants' rankings reflected their individual opinions regarding what projects are most important for ecologists to pursue. Principal component analysis (persons as variables) was used to identify groups of scientists with similar rankings, thereby revealing shared visions for ecology. Based on the eigenvalue scree plot, four resulting factors were rotated (varimax; Table 2). Strictly speaking, the factors are not groups of participants, but rather represent ideal types, or representations of ideas in the community. For ease of communication, I refer to these ideal types interchangeably as factors or "groups". Using standard methods (Brown 1980), I used weighted averaging to calculate each factor's average rating of each statement (Table 2). This calculation takes into account how accurately that factor represents associated participants' statement rankings when calculating that factor's average scores for the statements.

The next step in Q-method analysis is to identify the shared thought processes and logical structures that participants associated with each of the factors as they evaluated the merits of the statements. To accomplish this, I analyzed the interview responses, survey data, and statement evaluations using grounded theory, a qualitative data analysis technique used extensively by social scientists (Glaser and Strauss 1967; Miles and Huberman 1994). In grounded theory analyses, the investigator reads and re-reads the available data, evaluating and refining tentative explanations he or she built during ini- tial data collection. When those explanations are revised, the investigator revisits the initial data and repeats the process until the explanations are consistent with all available data. Through this inductive and iterative process, investigators are able to draw robust and nuanced conclusions from the qualitative and quantitative data that Q-method studies produce. Figure 2 depicts the methods used in this study in the form of a flow chart.

The factors reveal clusters of related perspectives and opinions about research priorities, but they do not represent actual people. The loading scores for each participant (WebTable 1), calculated during the principal component analysis, indicate how well that participant's ideas are depicted by each of the factor descriptions. Below, I describe the four factors that emerged from this analysis (see also Table 2). It is important to note that all participants expressed - to differing degrees - ideas associated with several factors. Also, there is considerable variability in the responses that is not explained by the factors described below, indicating that any participant may have some opinions not captured by the described factors. These limitations are present in all Q-method studies, since the goal of this method is to identify shared mental frameworks and no two people have identical opinions on any topic. In this study, several participants recognized that science plays multiple roles and suggested that their rankings might differ based on which of those roles he or she had in mind; we must therefore be cautious when trying to classify a person as being a "type". The factors are best thought of as characterizations of 


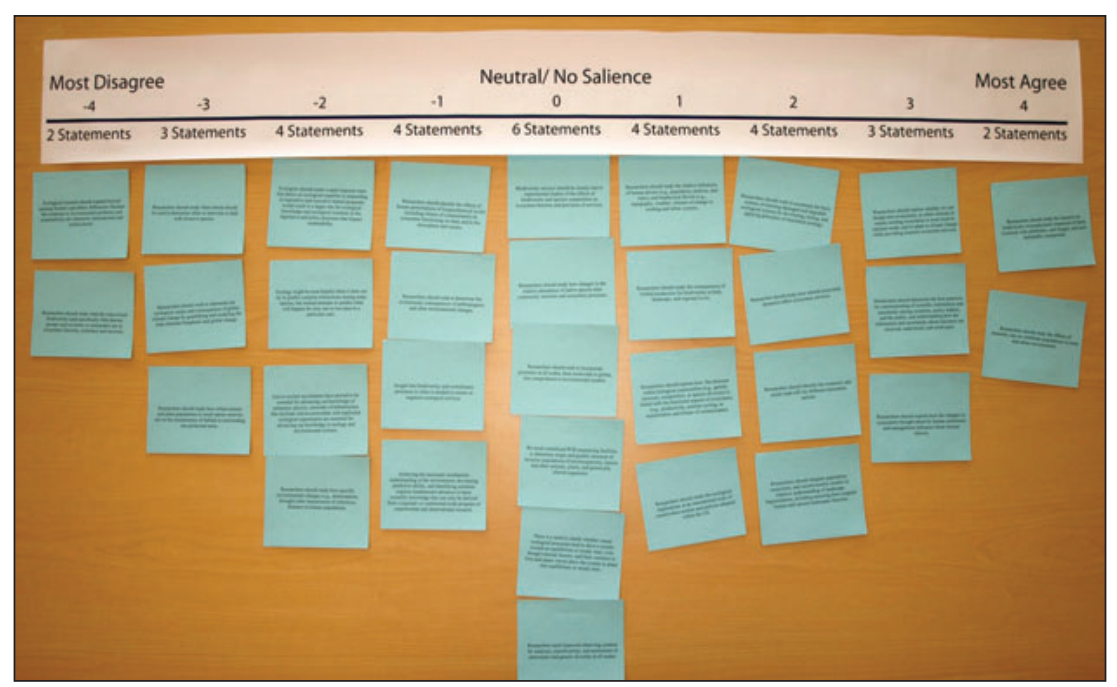

Figure 1. Participants were asked to rank the statements in terms of how well they agreed with each. They placed the cards they most disagreed with on the left and those they most agreed with on the right, and neutral or non-salient cards in the middle.

different logical or value structures present in the ecological research community about what constitutes worthwhile research. The factors are calculated based upon rankings of the priority statements, but the factor descriptions below are compiled through the grounded theory analysis, which is informed by the qualitative surveys and interviews.

\section{Factor 1: document problems and communicate findings to compel change}

Participants associated with this group believe that the main purpose of ecological research is to evaluate policies and human behaviors and thus to provide feedback to citizens and policy makers about the effects of their actions. Amassing a preponderance of evidence about anthropogenic impacts, this group believes, can compel leaders to make "better" policies and decisions. These participants selected their research priorities based on what they viewed as the most pressing environmental problems that they could conceivably influence through their work; they did not, however, agree about what the most pressing environmental problems are. Of those who felt that climate change is the most pressing environmental problem - and not all did - some felt obliged to study interactions between climate and ecosystems, based on a belief that additional research might reduce uncertainty or encourage policy and behavioral changes; others avoided the topic because they believed the politics surrounding climate change to be intractable.

For these participants, ecosystems have intrinsic value and should be preserved. Statements that suggested a need to improve our ability to restore damaged ecosystems and design new ones were treated coolly, in part because participants felt that these abilities would excuse further damage to comparatively intact systems. Statements interpreted by this group as merely building theory or advancing ecology as an intellectual pursuit rated poorly in contrast to those seen as compelling action.

Communication of science to the public and to policy makers was critically important to this group. Several made comments to the effect that policy problems result from a general lack of scientific knowledge amongst the public and policy makers. One participant said that solutions will only come about by "encouraging the non-scientist to understand the power of science"; another stated, "we seem to be speeding toward hell in terms of the environment, so communicating to the public is the only thing that will cause change". This group had strong policy preferences that they felt were founded on their scientific knowledge and believed that communicating this knowledge could lead to less damaging public policies and individual behaviors. They did not, however, always agree with one another's policy preferences.

\section{Factor 2: ecological theory that includes humans will guide policy, when communicated}

These participants believe that ecology can best inform policy and behavior by improving theory and communicating that knowledge directly to the public and to policy

Table 2. Summaries of and correlations between factors

\begin{tabular}{|c|c|c|c|c|c|}
\hline & & Factor I & Factor 2 & Factor 3 & Factor 4 \\
\hline & $\begin{array}{l}\text { Vision for } \\
\text { ecology } \\
\text { in policy }\end{array}$ & $\begin{array}{l}\text { Evaluate ecological effects } \\
\text { of policies and human } \\
\text { behaviors; amass evidence } \\
\text { to compel change; and } \\
\text { communicate findings }\end{array}$ & $\begin{array}{l}\text { Build theory of human } \\
\text { interaction with ecosystems } \\
\text { and communicate findings to } \\
\text { better inform policy } \\
\text { and behavior }\end{array}$ & $\begin{array}{l}\text { Build theory of ecosystem } \\
\text { function, publish findings, } \\
\text { but do not communicate } \\
\text { through other channels }\end{array}$ & $\begin{array}{l}\text { Inform ecosystem } \\
\text { management } \\
\text { and restoration }\end{array}$ \\
\hline & \# participants & 20 & 27 & 6 & 12 \\
\hline \multirow{4}{*}{$\begin{array}{l}\text { Correlations } \\
\text { between } \\
\text { factor } \\
\text { rankings }\end{array}$} & Factor I & 1 & 0.5841 & 0.1690 & 0.5408 \\
\hline & Factor 2 & 0.5841 & I & 0.2902 & 0.4152 \\
\hline & Factor 3 & 0.1690 & 0.2902 & 1 & 0.1272 \\
\hline & Factor 4 & 0.5408 & 0.4152 & 0.1272 & 1 \\
\hline
\end{tabular}


makers. As with the first group, these participants feel that ecology should address the scales and subjects they think are most relevant to environmental problems. One participant suggested that in order to select the most pressing problems, he has "come to believe that we need to find who's going to use [the information] and work backward. We need communication to guide us [in selecting research projects] at the beginning."

Only in this group did people use the term "socioecological system" to describe the realm of their priorities. As with Factor 1, few expressed concern that any statements were outside of the traditional bounds of ecology; several voiced the opinion that investigating human decision-making processes using the tools of social science is part of the discipline. People are components of ecosystems for this group. The historical failure of ecology to study human-dominated systems has artificially limited the relevance and explanatory power of the discipline. "Ecosystem services" is a popular term for this group because of its perceived effectiveness in communicating ecological ideas to non-scientists, a goal that they see as critical if ecology is going to contribute to policy making.

\section{Factor 3: stick to the science - build theory, but don't interact directly with policy}

For this group, ecology comprises experimentation, observation, and modeling in order to better understand ecosystem structure and function. As with participants associated with Factor 2, these ecologists believe that the way to inform policy is by furthering ecological theory. Unlike those associated with Factor 2, however, this group feels that ecology is damaged by direct engagement with policy and political processes, including communication with the public or policy makers. "Research", said one participant, "shouldn't be a lobbyist industry". Dealing directly with policy makers threatens ecologists' image of being "non-biased observers of what's happening in nature".

There is no consensus within this group as to whether people should be studied as part of ecosystems, but they uniformly believe that ecology should avoid questions that border on social science and economics. Those who feel that ecologists ought to study humans and humandominated systems believe that the work should be done using the techniques of classical ecology; that is, that humans should be treated as ecological actors and studied as just another organism.

\section{Factor 4: ecology should inform restoration and management}

Ecological knowledge is important for this group when it directly helps professionals manage and restore ecosystems; few are interested in informing other levels of policy. They seek to generate a clear ecological understanding of ecosystem function in order to create scientific principles for restoring that function. "Restoring [ecosystems]", one participant in this group characteristically declared, "seems more crucial than figuring out how the damage occurred". Within this broad rubric, these participants' individual policy preferences and favored ecosystems influence the specific questions that each prefers.

Participants associated with this factor supported some statements that others deemed to be important theoretical questions or critically linked to broad environmental policies. However, they value those statements only because of a perceived direct link to restoration and management. These participants gave varied responses about the desirability of studying humans as part of ecosystems and the responsibilities of ecologists in communicating their research findings to a broader audience.

\section{Discussion}

Humanity faces numerous complex environmental problems, each of which is open to multiple interpretations. What we know about these problems and their potential solutions comes in large part from formal scientific investigations of our world. However, the knowledge that science produces is a product of social processes. Asking dif- 
ferent questions would lead to different views of natural systems and of the threats to the environment (Haraway 1991; Hacking 1999b). Through the knowledge they generate and the way they choose to communicate it, scientists not only play a part in identifying policy problems and setting the terms of the debate about those problems, they also strongly influence how such problems are ultimately addressed. Scientists are policy actors, whether they intend to be or not. Understanding how and why scientists generate the knowledge they do is therefore important for designing science policies that ensure that research agendas are well aligned with democratically determined policy goals.

Although not intended as a random sample of ecologists, participants in this study were unified around a goal of generating knowledge to improve environmental decision making. That unity, however, masks a substantial diversity: participants' responses clearly showed that ecologists have differing concepts of the mechanisms by which their science should and does inform policy, varied interpretations of what constitutes environmental problems, and conflicting policy preferences. Some scientists aim to study issues they see as currently intractable, in the hope of providing additional evidence that would compel action; others prioritize research in areas where they perceive change to be politically or socially more easily attainable. Participants described these diverse considerations as they justified their research priority rankings.

Most participants felt they knew what the most pressing problems were, and many were confident that they knew both the solutions and what ecologists should do to ensure implementation of their preferred solutions. Most did not perceive these things as personal policy preferences, but rather as following directly from their science. They did not, however, agree with one another about these problems, nor about how ecology might contribute meaningfully to solutions. These different interpretations may be in part due to variability across regions where the scientists work and live, but participants had similarly varied interpretations of global phenomena, such as climate change and human population growth. This suggests that, even if the participants are correct in their assertions that their preferences flow incontrovertibly from their research, ecology cannot identify single-definition "best" outcomes and the policies that would achieve them. As such, ecologists may benefit from consulting others to help them define those "best" outcomes and identify research priorities that may contribute to achieving those results.

Although the diversity of approaches to determining research priorities might seem to be a sign of a healthy and robust discipline, problems can emerge when these considerations are not debated openly. In this study, diverse reactions to individual statements showed that projects perceived by some ecologists as critical are useless or even dangerous in the eyes of others, and these disparate evaluations exist even among ecologists with similar environmental policy objectives. The US's
\$433 million National Ecological Observatory Network (NEON; NRC 2003; Hopkin 2006; NSF 2010) offers a case in point.

The US National Research Council (NRC) issued a report in 2003, evaluating the NEON program (NRC 2003). A statement that "necessary mechanistic knowledge of the environment [can only come about from] a regional- or continental-scale program of experimental and observational research", which rated 29th in terms of overall popularity of the 32 statements used in this study, is one of the justifications the NRC used to support that project. Only participants associated with Factor 3 in this study rated the statement favorably; the others strongly rejected the proposition for a number of reasons, including: (1) the statement is factually incorrect, because important insights have come about through small-scale research; (2) mechanistic understanding of ecosystems is not possible; and (3) pursuit of the implied research would divert resources from more important efforts. Pursuing NEON, which outwardly appears to be an obvious and non-controversial decision about a necessary next step in ecological knowledge generation, is in fact contentious within the ecological research community. In explaining their support or opposition to the NEON derived statement, participants voiced different visions of which futures are most desirable, what policies might help us to achieve those futures, and what knowledge might bring about those policies. These are all considerations about which individuals and institutions outside of ecology could provide guidance, if research priority setting were a more open and accessible process.

The types of data that NEON is capable of collecting will influence what ecologists view as possible and desirable research, and will also affect policy debates about environmental issues (Haraway 1991; Hacking 1999a). Science policies - especially those involving infrastructure that will affect research portfolios for years to come deserve a broader and more open discussion regarding the purposes and promises of ecology. Ecological training and research provide ecologists with unique skills and insights, allowing them to evaluate what ecological conditions are possible in a given ecosystem, and giving them some level of insight about what those conditions might mean for society. However, determining which environmental policy objectives are most desirable is generally recognized as being within the purview of democratic processes. Once the desired objectives are democratically determined in a given situation (a process in which ecologists can play important roles), ecologists could increase their effectiveness in bringing about those outcomes by collaborating with others in establishing research priorities. Decision makers, political scientists, environmental psychologists, managers, and others could all help ecologists identify, in an iterative fashion, the research agenda that is most likely to inform efforts to achieve the desired outcomes. Not only would this help ensure that the knowledge scientists create is timely, credible, salient, 
and perceived as legitimate (Kinzig et al. 2003; Cash 2006), it would also allow ecologists to gain from others' insights about policy, politics, and human behavior. The process would of course be iterative and circular because additional knowledge gained through research may lead to a democratic revision of policy objectives. However, recognizing that those outside of ecology have a stake in the research agenda - and may in fact be able to provide key insights about what knowledge is useful - could help to ensure that ecologists are maximally productive in helping society to identify environmental problems and their solutions, a goal that all the scientists in this study aspire to.

\section{Acknowledgements}

With thanks to D Sarewitz, D Guston, M Harsh, E Fischer, E Corley, C Miller, A Smith, A Kinzig, and HR Zabaleta for critical feedback on this research, and L Hidinger and R Hudson for assistance with data collection. This material is based on work supported by the National Science Foundation (NSF) under grants $\# 0345604$ and \#0504248. Any opinions, findings, conclusions, and/or recommendations expressed in this material are those of the author and do not necessarily reflect the views of the NSF.

\section{References}

Barke RP. 2003. Politics and interests in the republic of science. Minerva 41: 305-25.

Brown SR. 1980. Political subjectivity: applications of Q methodology in political science. New Haven, CT: Yale University Press.

Cash DW. 2006. Countering the loading-dock approach to linking science and decision making. Sci Technol Hum Val 31: 465-94.

Chubin D and Jasanoff S. 1985. Special issue on peer review. Sci Technol Hum Val 10: 3-5.

Chubin DE and Hackett EJ. 1990. Peerless science: peer review and US science policy. Albany, NY: State University of New York Press.

Gieryn TF. 1978. Problem retention and problem change in science. Sociol Inq 48: 96
Glaser BG and Strauss AL. 1967. The discovery of grounded theory: strategies for qualitative research. New York, NY: Aldine de Gruyter.

Hacking I. 1999a. The social construction of what? Cambridge, MA: Harvard University Press.

Hacking I. 1999b. Weapons research: the social construction of what? Cambridge, MA: Harvard University Press.

Haraway D. 1991. Simians, cyborgs, and women: the reinvention of nature. New York, NY: Routledge.

Hopkin M. 2006. Ecology: spying on nature. Nature 444: 420-21.

Kinzig A, Starrett D, Arrow K, et al. 2003. Coping with uncertainty: a call for a new science-policy forum. Ambio 32: 330-35.

McKeown B and Thomas D. 1988. Q methodology. Newbury Park, CA: Sage Publications.

Merton RK. 1979. The sociology of science: theoretical and empirical investigations. Chicago, IL: University of Chicago Press.

Miles MB and Huberman AM. 1994. Qualitative data analysis: an expanded sourcebook. Newbury Park, CA: Sage Publications.

Neff MW and Corley E. 2009. 35 years and 160000 articles: a bibliometric exploration of the evolution of ecology. Scientometrics 80: 657-82.

NRC (National Research Council). 2003. NEON: addressing the nation's environmental challenges. Washington, DC: The National Academies Press.

NSF (National Science Foundation). 2010. FY 2011 budget request to Congress: major research equipment and facilities construction. Arlington, VA: National Science Foundation.

Polanyi M. 1962. The republic of science: its political and economic theory. Minerva 1: 54-73.

Rip A. 1985. Peer review is alive and well in the United States. Sci Technol Hum Val 10: 82-86.

Robbins P and Krueger R. 2000. Beyond bias? The promise and limits of Q method in human geography. Prof Geogr 52: 636.

Salazar DJ. 2009. Saving nature and seeking justice: environmental activists in the Pacific Northwest. Organ Environ 22: 230-54.

Weinberg AM. 1963. Criteria for scientific choice. Minerva 1: 159-71.

Woolley JT and McGinnis MV. 2000. The conflicting discourses of restoration. Soc Natur Resour 13: 339-57.

Worster D. 1994. Nature's economy: a history of ecological ideas, 2nd edn. Cambridge, MA: Cambridge University Press.

Ziman J. 1981. What are the options? Social determinants of personal research plans. Minerva 19: 1-42.

Ziman JM. 1987. The problem of "problem choice". Minerva 25: 92-106.

Zuckerman H. 1978. Theory choice and problem choice in science. Sociol Inq 48: 65

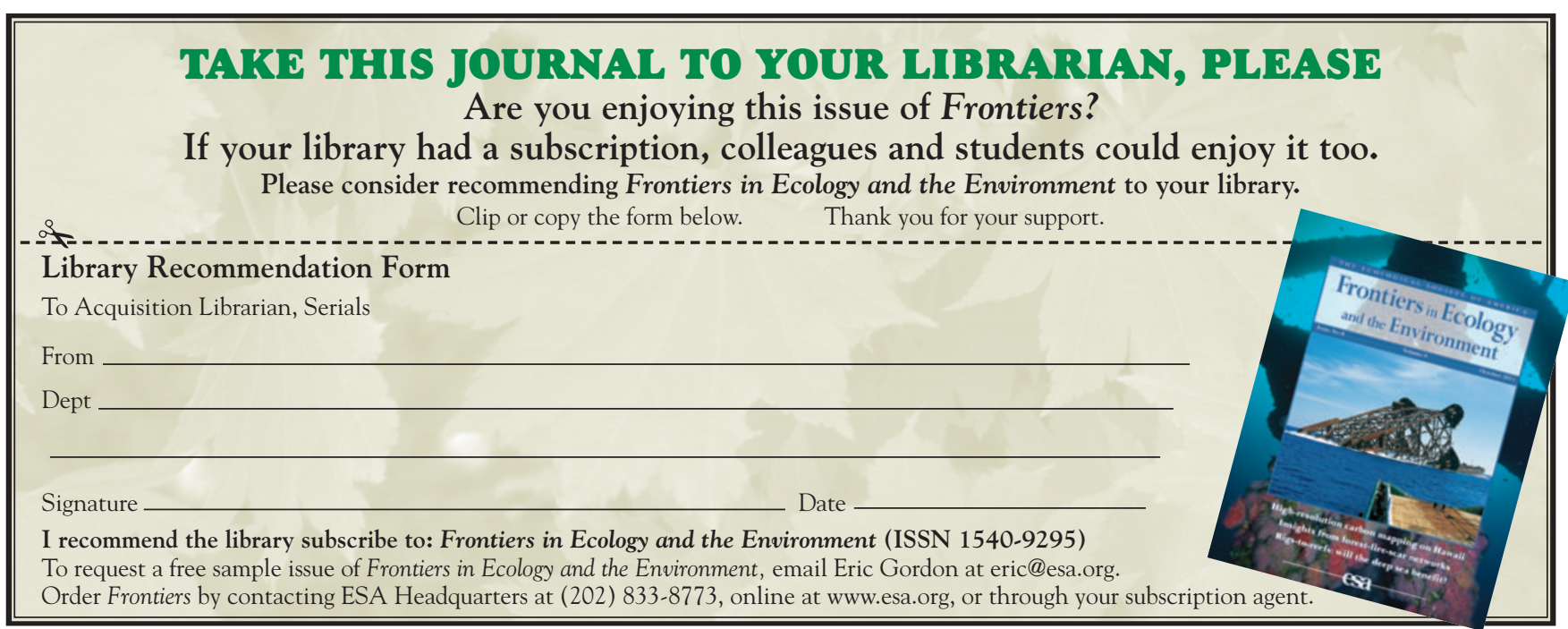

(C) The Ecological Society of America

www.frontiersinecology.org 